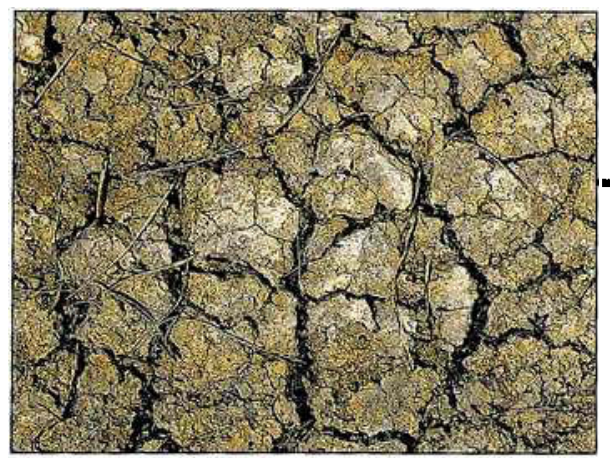

When water is scarce...

\title{
Ground water is key to easing impact of drought
}

Richard E. Howitt

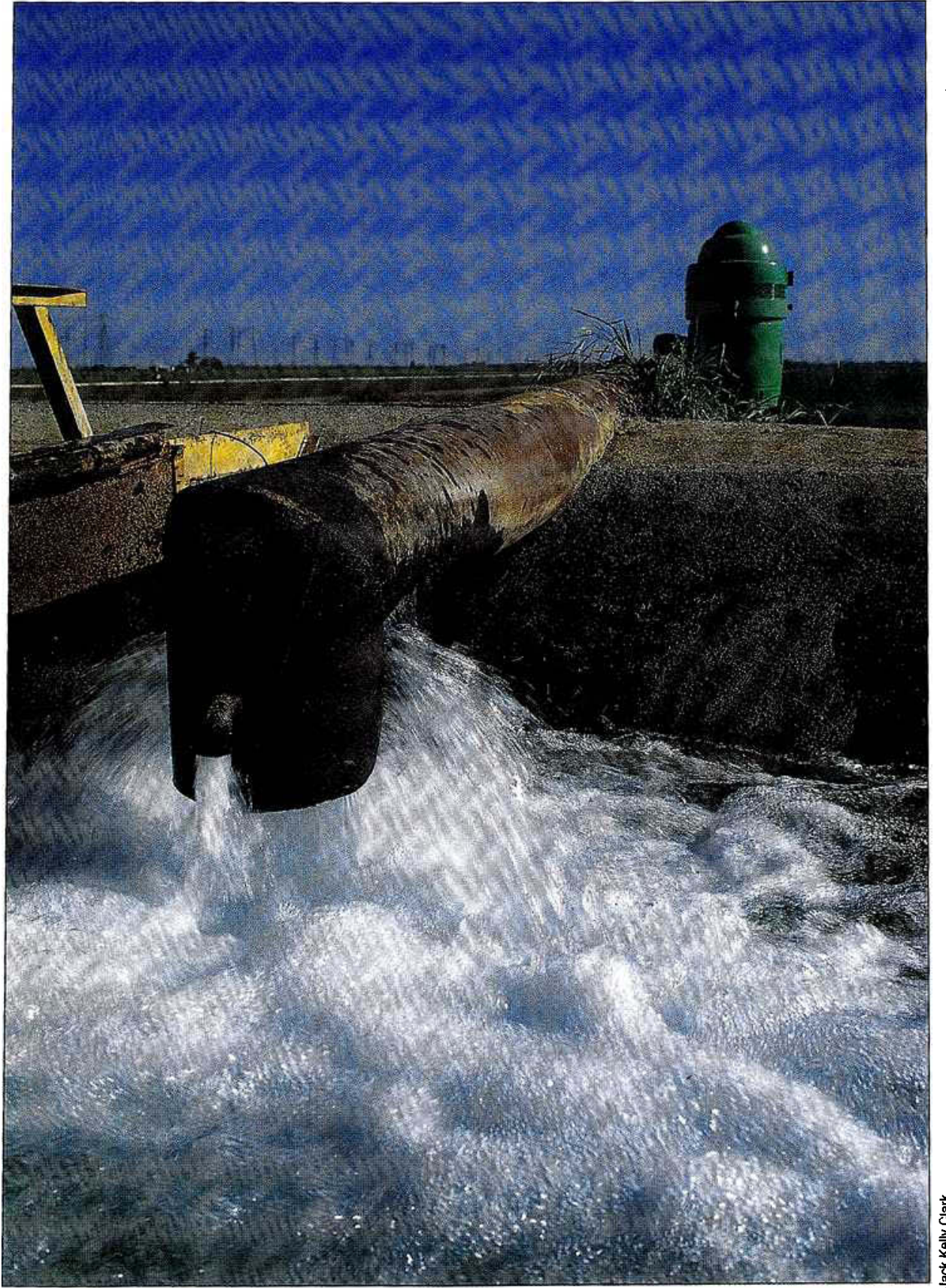

Ground water flows into irrigation canals near Winters in Yolo County.
In contrast to projections that drought-related farm losses could climb to several billion dollars this year, a UC model predicts actual losses will be $\$ 647$ million largely due to the cushioning effect of a projected $70 \%$ increase in ground water pumping. The most significant economic impact will be felt in the South San Joaquin Valley, and along the Coast. Consumers will pay $\$ 220$ million more for produce at the farm gate-an amount that may be magnified two or three times at the retail market.

On page 6, the author and a colleague outline a scenario for ground water banking. They propose incentives to encourage ground water "savings" during wet and normal years - deposits to a "water bank account" which can be withdrawn in droughts.

In 1977, California entered the second year of the state's worst drought since the early 1930s. Predicted agricultural losses ranged from $\$ 2.4$ to $\$ 6.3$ billion. Yet one year later, growers reported a 1977 net farm income that was the second highest ever recorded and very close to the predrought average of 1973 to 1975 (fig. 1). What happened?

First, farmers and water districts were able to offset much of the drought shortfall by greatly increasing ground water pumping (fig. 2). Second, the drought tended to drive up prices for those crops in which California specialized. However, because ground water pumping increased markedly while farm prices rose only slightly, we can conclude that ground water was 
the chief factor in easing the impact of drought.

In 1991, a year of continuing surface water shortages, the grower's ability to pump ground water and transfer surface water has proven essential to limiting economic loss. Such flexibility can again be expected to cushion the drought's effects on farm production, farm income and consumer prices. To provide an objective forecast of statewide agricultural losses this year, we used the California Agriculture and Resources (CAR) model developed at UC Davis. Although our assumptions concerning water supplies, distribution and cost reflect critical drought conditions prevalent before the recent spring storms, 1991 is still a relatively dry year and holdover storage in the state's surface reservoirs remains low.

The CAR model predicts farm income losses of $\$ 647$ million in irrigated agriculture, with the greatest losses sustained by the South San Joaquin Valley $(15.7 \%)$, the North Coast $(17 \%)$, and the Central and South Coast (10.3\%). It also predicts consumers will pay an additional $\$ 220$ million during 1991 at the farm gate - a figure that could be magnified two or three times at the retail market.

With California drought occurring historically three years in every ten, these findings underline the need to manage ground water quality and quantity. The projected $70 \%$ increase in ground water pumping this year will result in a marked increase in ground water overdraft. Even in normal rainfall years, the Department of Water Resources estimates that Californians overdraft 2 million acre-feet of ground water annually. The scarcity of water is exacerbated by the state's popula-

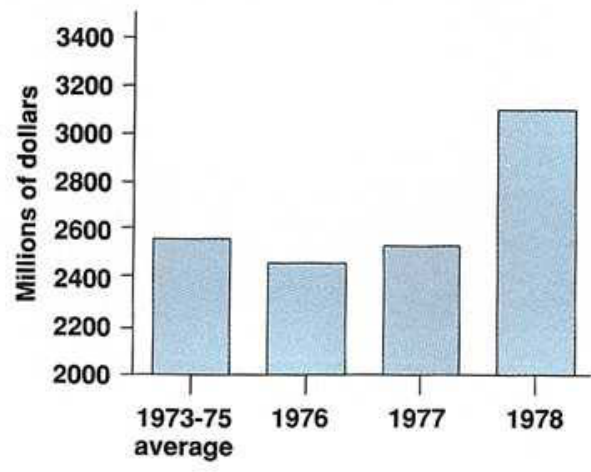

Fig. 1. California's net farm income in 1976, 1977 , and 1978 compared to the 1973-to-1975 average.

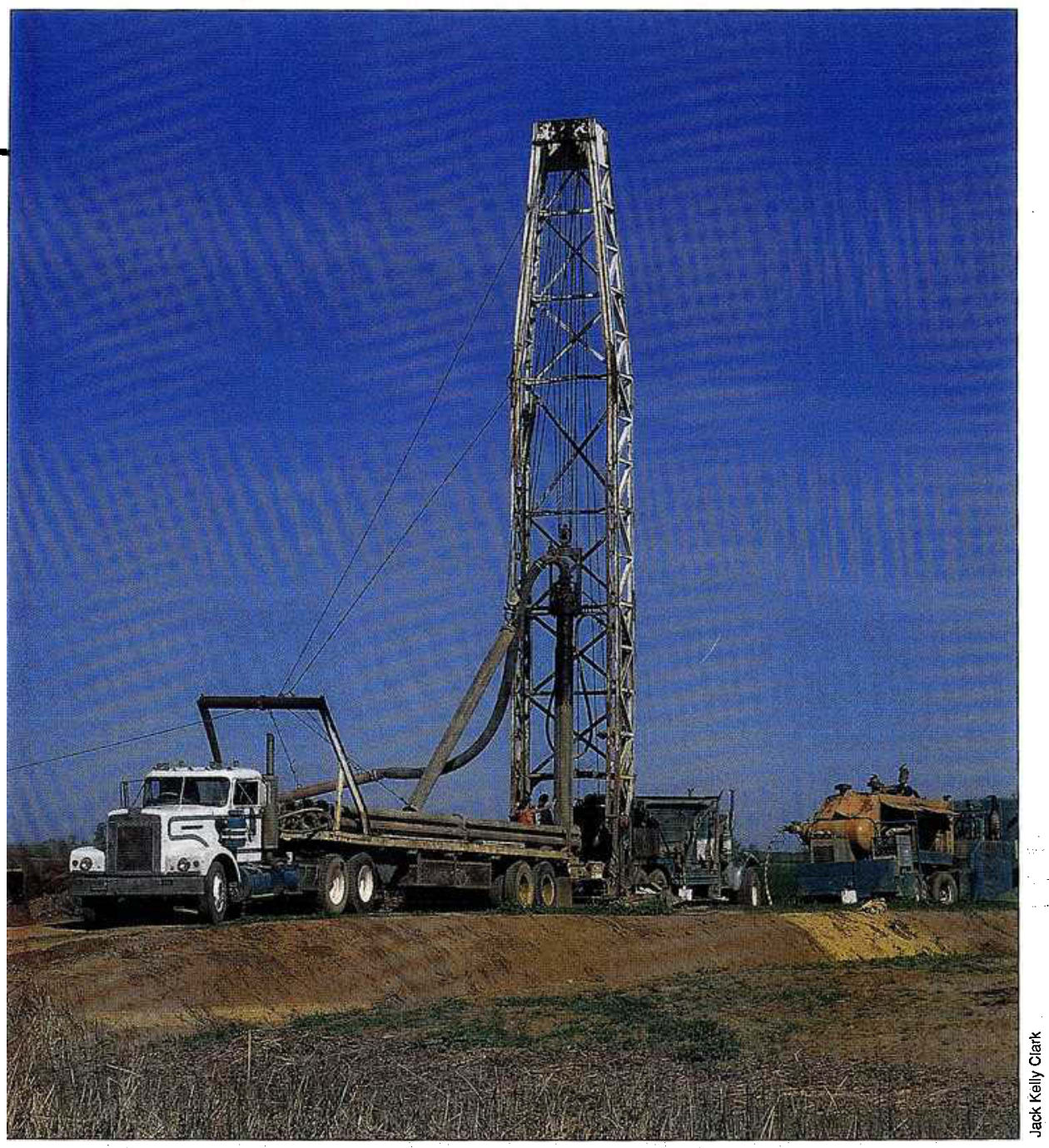

Drill rig used to ream the borehole for a new water well west of Davis.

tion growth; 700,000 new Californians a year increase urban water demand by 100,000 acre-feet annually. California's ground water resources are finite and yearly overdrafts cannot continue indefinitely. Only by conserving ground water

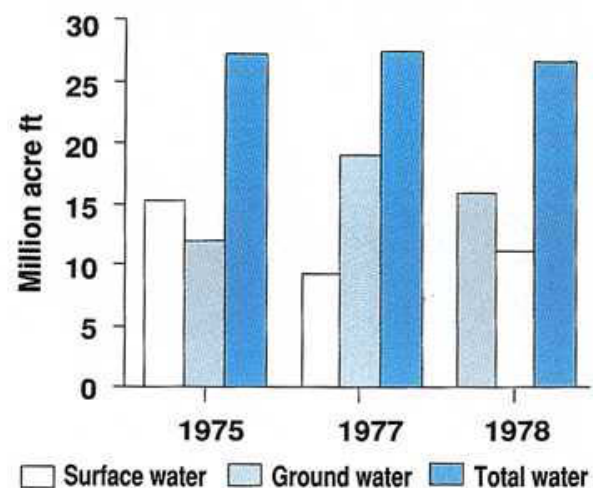

Fig. 2. Agricultural water use in 1975, 1977 , and 1978. in normal and wet years, can the flexibility of this essential resource be maintained.

\section{How the CAR model works}

The current version of the CAR model divides the state into 6 agronomic production regions and includes more than 40 annual and perennial crops. For each crop, prices received by California growers are related to quantities marketed here and elsewhere, demand shifts, input and resource costs, and other factors such as water availability and cost. The model shows reactions of both producers and consumers. Crop acreages, yields and prices are derived from county agricultural commissioner reports; production costs from the California Cost of Production Survey (1987 crop year); and crop water use and regional water availability from the California Department of Water Resources.

The CAR model forecast of the effects of the 1991 drought was based on four assumptions: 
in California's Central Valley. (Surface water flows in any given year are measured by an index of the flow in four key rivers: the American, Sacramento, Feather and Yuba Rivers.) If there are no retroactive fixed demand charges, a determination in February or March each year would enable growers to respond with normal or dry year pumping strategies.

Two problems arise from the outline of this ground water banking scheme. First: What if pumpers don't react to the demand cost reductions?' The answer would be to also tilt the power rates in the direction of the set aside program. Domestic energy users have responded to time of use and efficiency incentives offered by utilities. Agricultural well pumpers are now faced with a range of rate schedules. Their response to these rate changes would enable a program to be developed.

A second problem that does not have an easy answer is: 'What stops a pumper from putting one well in the set aside program and pumping additional water in normal years from an adjoining well?' The answer is that nothing can be done about this problem under existing ground water rights. The degree of slippage in the program due to this switching needs to be estimated.

\section{Summary}

Normal years are not normal in California's variable water supply. The most common occurrence is a wet or a dry year. Droughts are the dominant consideration in planning surface water systems. The ability to respond under drought conditions is a very valuable aspect of California's ground water resources. However, given the persistent overdrafts of ground water in normal years, the ground water stocks and extraction capacity may be lacking in future droughts.

As California's water supplies get increasingly costly and scarce, ground water use must respond to the natural variability. Ground water pumpers have shown that they can respond, but the incentives to maintain this ability to respond to drought are currently absent in California's pumping rate structure. A self financing ground water banking program could provide an alternative incentive structure that would maintain a flexible response.

R.E. Howitt is Professor, Department of Agricultural Economics, UC Davis, and $M$. M'Marete is Operations Research Specialist at the California Department of Water Resources.
First assumption: Surface water supplies to agriculture would be cut by an average of $80 \%$. (This reflects announcements made before the recent March storms of $100 \%$ cuts by the State Water Project, $75 \%$ cuts by Federal Central Valley Project and similar cuts by other water supply agencies.)

Second assumption: Ground water pumping would increase up to $70 \%$, a figure based on past experience and current well capacity. As a result, net water use would drop somewhat, but far less than the reduction in the surface supply. The assumed net regional reductions in irrigation water use were:

- Sacramento region (Tehama, Glenn, Butte, Colusa, Yuba, Sutter, Yolo, Sacramento, Solano Counties): $12 \%$.

- North San Joaquin Valley (SJV) region (San Joaquin, Stanislaus, Merced Counties): $17 \%$.

- Central SJV region (Madera, Fresno, Tulare, Kings Counties): $20 \%$.

- South SJV region (Kern County): $30 \%$.

- Bay Area and Northern Coastal region: $10 \%$.

- Central and South Coast region: $35 \%$.

- Imperial and Coachella Valley region: No reduction.

For the entire Central Valley, the average 1991 reduction in water use was assumed to be just under $18 \%$. (This is a weighted average, taking into account regional water use in a normal year.)

Third assumption: Average water costs to farmers would double. This figure used by the CAR model is, obviously, an estimate. It is based on the following reasoning: Farmers would have to pay some fixed charges for surface water even if they did not receive it. Furthermore, ground water pumping costs would be higher than normal because of higher power rates, deeper depths and use of some less efficient pumps. Part of the available surface water would come from transfers costing $\$ 130$ or more per acre foot even before conveyance. Overall, doubling of water costs is an ad hoc assumption, but probably not far off.

Fourth assumption: Perennial crops, with most capital cost and crop income at risk, would bid most for the scarce supply; as a result, sufficient water would move within regions so that $95 \%$ of tree and vine crops would produce normal yields. Thus, perennial crop producers would find it worthwhile to buy water from the Water Bank for $\$ 140$ plus conveyance costs. It was also assumed that annual crops would not be planted unless the grower had a reasonable expectation of enough water to bring the crop to maturity. Therefore, per-acre yields of the annual crop acreage that is planted would be close to normal.

\section{Impacts on acreage}

Using these assumptions, the CAR model projected statewide crop acreage changes during the 1991 drought-impacted growing season. Estimated changes for those crops most affected are shown in table 1.

Differences among the various crops in the table are largely due to the fact that greater decreases in acreage can be expected for (1) higher water-use crops and (2) lower per-acre value crops. Irrigated pasture, for example, fits both of those categories; and irrigated pasture is projected

\begin{tabular}{|lcc|}
\hline \multicolumn{1}{|c|}{ TABLE 1. Projected acreage changes given the 1991 drought assumptions } \\
\hline \hline & Acres removed & $\begin{array}{c}\text { Percentage reduction } \\
\text { below } 1987 \text { - a normal year }\end{array}$ \\
\hline & $\times 1000$ & $\%$ \\
Total & $1,252.0$ & 14 \\
Crops with major & & \\
changes & & \\
Alfalfa hay & & \\
Cotton & 293.0 & 28.7 \\
Silage & 280.5 & 23.0 \\
Melons & 17.5 & 11.0 \\
Rice & 19.4 & 15.7 \\
Sugar beet & 33.9 & 8.7 \\
Irrigated wheat & 40.1 & 17.6 \\
Irrigated barley & 52.6 & 10.7 \\
Grain sorghum & 45.3 & 27.7 \\
Pasture & 5.8 & 32.2 \\
\hline
\end{tabular}


for the largest acreage reduction of all, almost one-third. Other crops with substantial projected drops in acreage are grain sorghum, alfalfa, irrigated barley and cotton.

The total reduction in Central Valley acreage of 10 leading crops (14\%) is less than the projected $18 \%$ overall drop in water use. Again, this is because some high water-using crops were expected to be reduced disproportionately.

\section{Impacts on prices and income}

To the extent that cuts in acreage result in less production of various crops, farm income will be affected. However, the grower's financial loss will not be in direct proportion to his reduced yield, because prices can be expected to strengthen at least slightly in response to lower production. Price responses of several dozen important crops are built into the CAR model. Crops showing most flexibility (greater price responses to a given change in production) include celery, lettuce, wine grapes, avocadoes, plums, safflower, citrus and rice. Crops with least flexibility are alfalfa hay, alfalfa seed, barley, corn, cotton, grain hay, grain sorghum, silage and sugar beets.

Given the foregoing assumptions about water supply, water costs, acreage reductions and lower output in 1991, what price impacts related to drought could be expected for various crops? The CAR model's projections for 10 representative crops are shown in table 2.

How would these acreage and price changes affect farm income? Table 3 shows the CAR model's projections, amounting to a total loss of $\$ 647$ million in

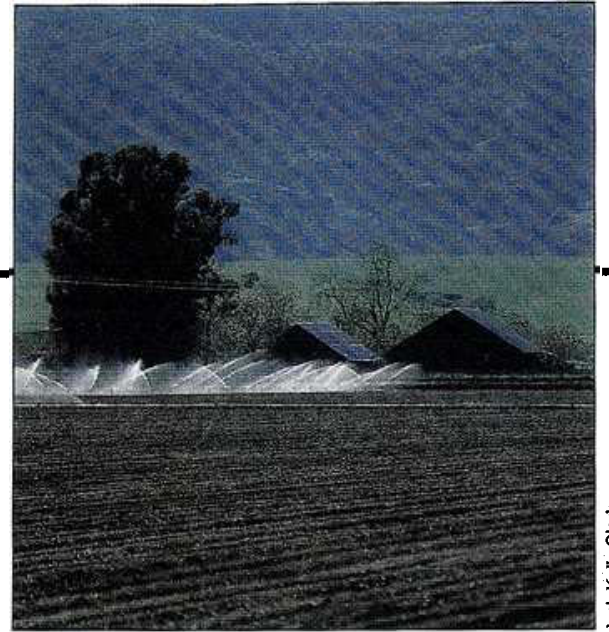

Farm near Winters.

net farm income. The highest dollar loss, more than $\$ 275$ million, is forecast for the Central and South Coast regions, where a $35 \%$ cut in irrigation water supplies is assumed for 1991.

A loss of more than $\$ 163$ million, is forecast for the Central San Joaquin Valley region. That is $5.4 \%$ of the region's expected returns to land and management. A somewhat lower dollar loss (\$122 million) - but a much higher percentage of returns loss $(15.7 \%)$ - is indicated for the South San Joaquin Valley.

Consumers also have a stake in the drought's impact on California agriculture. The CAR model projects that consumers will pay an additional $\$ 220$ million during 1991 at the farm gate - a figure that could be magnified to $\$ 440$ or $\$ 660$ million in the retail food system. (The exact impact of increased farm prices on retail prices is unknown. However, the average proportion of farm value in retail prices is $24 \%$. Furthermore, unpredictable seasonal factors may increase prices even more.)

Increased consumer costs will be concentrated in those crops that show large farm price changes: fruits and manufactured dairy products, the latter due to in- direct feed costs. Estimates were calculated by measuring the extra amount that purchasers would have to pay for produce under drought conditions, and also the loss of consumption benefits for those who could not, or would not pay the higher prices for reduced quantities. Calculations were based on 23 years of data describing consumer behavior.

\section{Conclusion}

In addition to the need for objective analysis of probable impacts on agricultural output and prices, two other lessons can be learned from the droughts of 1977 and 1991.

First, if surface supplies of irrigation water can be readily moved from lowvalue to high-value uses within agriculture by a market or water bank method, the total impact on farmers, urban areas and consumers of food will be greatly reduced.

Second, ground water is California's key water resource; and the ability to use ground water conjunctively with the surface supply is its most valuable characteristic. It is vitally important to take advantage of wet years as an opportunity to reduce use of ground water and recharge the supply. It is also vitally important to protect ground water quality.

R. E. Howitt is Professor, Department of Agricultural Economics, UC Davis.

The author acknowledges the assistance of Ray Coppock, writer at the Agricultural Issues Center

This manuscript summarizes major conclusions from a position paper published by the Agricultural Issues Center.
TABLE 2. Projected "farm gate" price changes due to drought given the 1991 drought assumptions

\begin{tabular}{lc}
\hline Crop & $\begin{array}{c}\text { Percentage of price } \\
\text { increase }\end{array}$ \\
Alfalfa hay & 5.7 \\
Barley & 1.8 \\
Cotton & 3.6 \\
Melons & 6.1 \\
Raisins & 1.8 \\
Rice & 6.3 \\
Safflower & 12.8 \\
Silage & 2.4 \\
Wine grapes & 2.5 \\
Wheat & 2.2 \\
\hline
\end{tabular}

TABLE 3. Projected regional net farm income

\begin{tabular}{lcc}
\hline Regions & Loss of net revenue & $\begin{array}{c}\text { Loss of returns to land } \\
\text { and management* }\end{array}$ \\
\hline Sacramento & million \$ & $\%$ \\
North San Joaquin & 46 & 4.0 \\
Central San Joaquin & 19 & 2.0 \\
South San Joaquin & 163 & 5.4 \\
North Coast & 122 & 15.7 \\
Central and South Coast & 22 & 17.0 \\
Total & 275 & 10.3 \\
\hline
\end{tabular}

*Returns to land and management are defined as gross income minus average operating costs. The portion of returns to land and management that remains as profit is seldom above $10 \%$ to $15 \%$ and may be less. Reductions of $10 \%$ or more could eliminate farm profits.

Note: These figures are for irrigated agriculture, and do not include drought losses suffered by range livestock operators and growers of dryiand crops - which may be substantial. 